\title{
Project Management Techniques to Maximise Success with Research.
}

\section{Learning objectives}

1. Understand how project management principles can support the management of your research project

2. Understand how to identify the key risks that may challenge your research project

3. Understand how to use SMART principles to ensure that your research project is achieved

\section{Definition of a project}

Globally, coronary heart disease remains one of the biggest causes of death (WHO 2013) and has influenced a vast array of research to ensure that treatments, approaches, prevention strategies and rehabilitation methods are evidence based. Significantly, the amount of public and private funds used to support research in cardiac care is vast, and funders expect timely, high quality research to develop and take forward care delivery innovations. Managing research can be complex and fraught with challenges, however, careful consideration of the risks and how these can be avoided or managed can increase your chances of success.

By nature any project is a 'a temporary organization and process setup to achieve a specified goal under the constraints of time, budget and other resources' which require robust management principles (Snehar \& Dvir 2007). Research projects are temporary projects with a clear aim designed to follow a research design, to find out about a particular phenomena within the designated time and resource constraints. Good project management can maximise success with research projects. This paper will explore how project management principles can be applied to research projects in cardiac care to ensure that they are successfully completed on time, and within budget.

\section{Key Principles of Managing a Project}

The failure of research projects is often due to a lack of planning. It can be argued that it you fail to plan, you plan to fail! Ambiguous objectives, timescales, budget, lack of defined roles, ambiguity of purpose can lead to frustration and challenges. The key principles associated with successful research project management include clear objectives, a full appraisal of all options, identification of risks, inclusion and analysis of stakeholders' perspectives, a strong communication strategy, methods to manage time and outcomes that can be captured through project evaluation at the end. (see figure 1).

\section{Figure 1: Key Steps in Project Management}

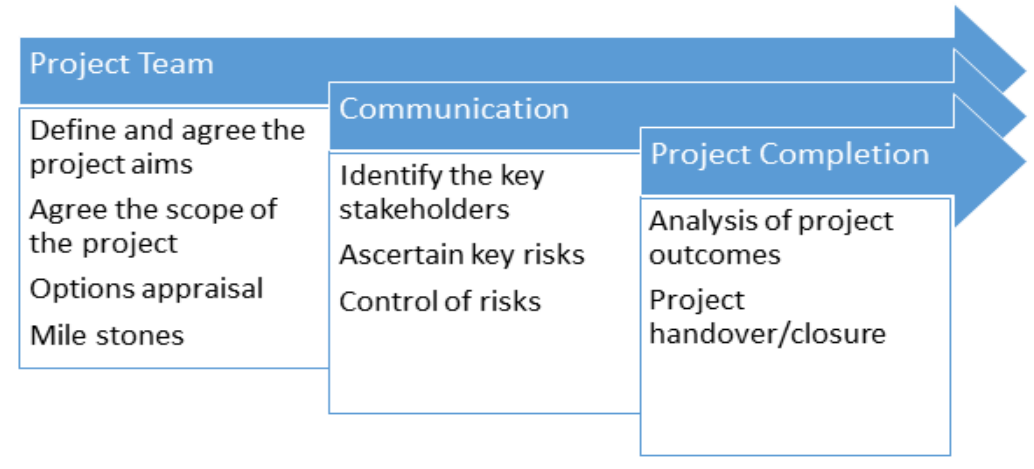


The key steps in project management in Figure 1 illustrate the continued need for the project team to work together, and to communicate through the lifetime of the project and beyond to ensure that the project achieved. This will ensure that all the key steps are managed communicated and actions developed to facilitate the success of the project.

\section{Define and Agree Project Aims:}

Martin (2002) advises that a project is a one off activity that is not normally repeated, hence, all projects need a clear purpose, clear end and outcomes. For example, if a recent patient satisfaction survey revealed that patients left hospital anxious about their future following a CABG, you may want to evaluate the recent implementation of an additional discharge service to ensure that patients are visited in their own homes within 2 days of discharge. Your research project should have SMART outcomes: Specific, Achievable, Measurable, Realistic, and Timed. Figure 2 below illustrates how your project could be SMART.

To survey the impact of a post discharge service on the anxiety of patients post first time isolated CABG within 12 months.

\section{Figure 2: SMART objectives}

\begin{tabular}{l} 
- To evaluate post discharge service with patients who have been discharged from \\
hospital within 2 days following an isolated first time CABG using a survey \\
\hline - The outcome measurement is clear and will assess the anxiety levels of patients \\
using a validated survey tool. \\
- No other patient groups will be included. The aim is to capture the views of 200 \\
patients using a structured, validated survey. \\
- The project is realistic because the sample size is achievable within the time scale \\
and the outcomes are clear. \\
- The project wil be completed within 12 months. This includes data collection, \\
analysis and reporting of the findings to the key stakeholders. \\
\hline T
\end{tabular}

This project aim is SMART because it includes a specific goal (post discharge service), the sample population which the project will access (patients post CABG), and the date that this needs to be achieved by. This ensures that the project is 'realistic' and timed. The outcomes of the project and the evaluation are measurable (date of completion, impact on anxiety). Further objectives can be included to help achieve the aim and to ensure that the project is timed and managed.

\section{Scoping the Project:}

Typically, project designs are first explored within the 'scope' of your project. To scope your project, you need to consider what is included, and what isn't. The scope should help visualise the lifespan of your research project and set parameters. For example, the project to measure anxiety levels of patients post discharge includes one patient group and will only collect data from 200 patients. It is 
tempting to want to evaluate everything, however, research can only answer one question at a time; equally, projects should not become too large that the aims are unrealistic to accomplish.

\section{Weigh up the Options:}

Once you have determined the aims and objectives, you then need to explore whether the project benefits are worth the cost and the risk, and which method will deliver the desired outcomes, at the right time and at an acceptable cost and level of risk. For research projects this includes identifying the most appropriate methodological design and ensuring that the data collection tools and analysis will achieve the aims of the research project. You will need to determine the associated costs of the overall research design to ensure that your research funds are able to cover the resources required for a successful project. This includes for example, any data collection costs, such as transcription costs, survey dissemination or it may also include interventions as part of an experimental study. Researcher and participant time, staff resources, equipment and other costs such as travel, subsistence and overheads will need to be included in your options appraisal. The costs associated with the post discharge survey may include printing costs, postage, analysis software, staff time and reporting costs.

\section{Milestones; Planning and Charting your Project Outcomes}

Project milestones usually guide the parameters of the project and are based on the critical points at intermediate and final stages of the project lifespan. According to Loo (2003), milestones are key to the design and management of projects are predicated on key decisions that must be made. For example, critical points of the project may include securing funding to support your research, gaining ethical approval, gaining access to the sample population, report data collection and analysis activities and report wrong. Project management often use a 'Gantt chart' to plot the milestones against the calendar lifespan of the project. Milestones can help determine the outcomes for success and enable you to plan steering group meetings around critical events. It is good practice to include "slippage" time in your Gantt chart to enable you to plan for and manage unforeseen challenges that may cause a delay to your project.

\section{Example of a Gantt Chart}

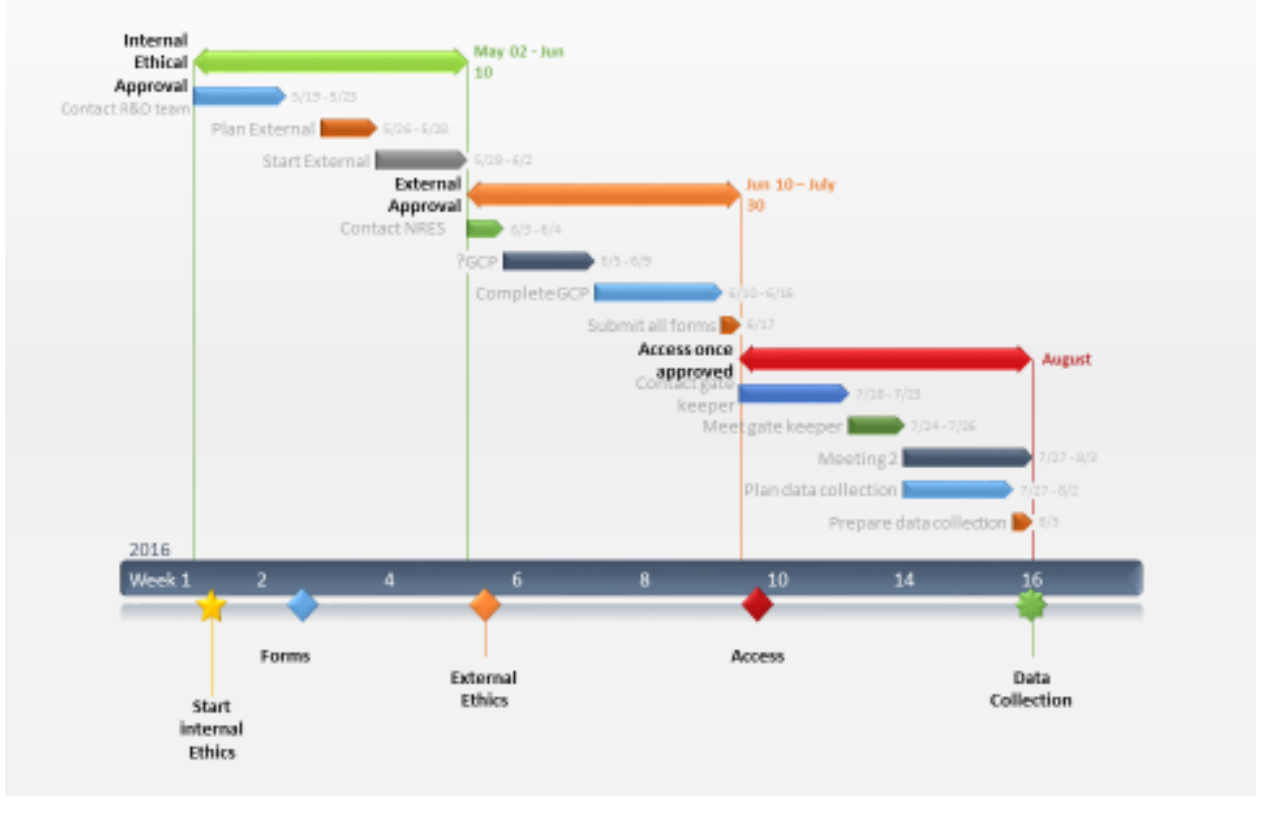




\section{Identify \& Manage Key Stakeholders:}

Stakeholders are people who have a vested interest in your project. The analysis and identification of key stakeholders is imperative to project success (Cooper et al, 2005; Ward and Chapman, 2008). They can influence the design and development process so you need to ensure that all the key stakeholders are identified and managed. Stakeholders can include the sponsor or client, managers within the organisation, individuals or groups affected by the project and key representatives (Martin 2002). In research projects, key stakeholders include gatekeepers - for example, those people whose approval is required to access your sample population, and patients/service users providing patient and public involvement (PPI). You need to gage and use the opinions of the most powerful stakeholders to shape your projects at an early stage. There are a number of methods that you can use to map your key stakeholders and ensure that you have considered their influence. The NHS Institute for Innovation and Improvement (2010) advise the use of a four or nine sector mapping tool to identify those stakeholders that have the greatest power and influence and those that have low power and influence.

\section{Weigh Up the Risks:}

All projects include some element of risk. The severity and potential impact of all risks needs to be carefully considered and assessed. Risks to the research project could include staff resource, sickness, recruitment, time slippage and unexpected delays. Assessing risks early on in the project can help you to minimise or mitigate these to ensure that your project runs smoothly. The UK National Patient Safety Agency advises that the likelihood of all potential consequences should be identified. Secondly, the likelihood of these risks should be calculated, for example, negligible $=1$, minor $=2$, moderate $=$ 3 , major $=4$, catastrophic $=5$. Finally, the risks should be scored to highlight the potential severity and impact on the project. This includes scoring risks as extreme, high, moderate and low. A colour coded system using red (extreme), amber (high), yellow (medium) and green (low) is often used to illustrate the high to low risks. Once the risks have been scored, an action plan to help mitigate and reduce the risks can be developed. For example, a key risk associated with survey is poor response rate - to reduce this risk you may include strategies such as follow up reminders.

\section{Project Completion:}

The project is complete once all the aims and objectives have been realised. Using your Gantt chart to measure the milestones and ensuring regular communication between the project team and key stakeholders will enable you to determine whether the project has achieved the aims. Analysis of the aims should be based on the original outcomes used to develop your SMART objectives. For example, the project was to "qualitatively evaluate the impact of a post discharge service on the anxiety of patients post CABG by a proposed date". There are key outcomes and milestones needed to accomplish this, including ethical approval, access to your sample, collection and analysis of data and finally report writing and dissemination. Once these milestones are achieved the project is completed.

\section{Summary:}

To undertake a project requires thought and attention to detail. Significant time needs to be devoted to the specific aims and expected measurable outcomes of the project. Without such attention to detail, the project will lack focus. Attention to determining goals and questions to guide the process are crucial and following the SMART acronym should facilitate a clear definition of what is to be accomplished and specifically how. Engaging stakeholders early in the preparation and design of the project ensures that an eye is kept on how different conclusions could affect outcomes and also provides an opportunity for continuous feedback. Follow up meetings with intended users to facilitate 
the transfer of findings into practice interactions and decision making gauges demonstration of positive evaluation. A successful project outcome is more likely to occur when the project manager has identified and eliminated (wherever possible) potential risks before they actually occur. By estimating the probability and consequences of actual and potential risks the potential to detect an issue and the severity of that issue may be eased. Follow the tips below to make your research project a reality.

\section{Top tips tick box}

1. Make sure your project is SMART

2. Explore all the available options

3. Plan and chart the project milestones

4. Gain support from key stakeholders

5. Assess the risks

6. Ensure you have a robust communication strategy

7. Embed an evaluation strategy linked to your objectives.

\section{Activity: 1 Stakeholder Analysis}

1. Make a list of all the potential stakeholders in the post discharge CABG evaluation

2. Limit the list to the 'key 9 players' - those that are considered to be most influential

3. Map out the stakeholders to determine who has most power/most influence and least power/least influence.

\section{Activity: 2 Risk Management}

1. List the potential risks to the evaluation of the post discharge CABG service -

2. Score the potential consequences of the risks (1-5)

3. Determine the likelihood of the risks (extreme - low)

4. Colour code the risks using red, amber, yellow, green.

\section{References}

Cooper, D, F., Grey, S,, Raymond, G., Walker, P. (2005) Project risk management guidelines managing risk in large projects and complex procurements ISBN 0-470-02281-7

Loo, R. (2003). Project Management: A Core Competency for Professional Nurses and Nurse Managers. Journal for Nurses in Staff Development. Vol: 19, No. 4, pp: 187-193

Martin, V. (2002) Managing Projects in Health and Social Care. Routledge. London. 
NHS Institute for Innovation and Improvement (2010) The Handbook of Quality \& Service Improvement Tools. HMSO: London.

Shenhar, A., J., Dvir, D. (2007). Project management research-the challenge and opportunity. Project Management Journal; Vol: 38, No. 2; pg. 93-100.

Ward, S., \& Chapman, C. (2004). Making Risk Management More Effective. In P. W. G. Morris \& J. K. Pinto (Eds.), The Wiley Guide to Managing Projects. Hoboken, New Jersey: Wiley \& Sons, Inc.

Winter, M., Smith, C., Morris, P., Cicmil, S. (2006) Directions for future research in project management: The main findings of a UK government-funded research network. International Journal of Project Management. 24 pp: 638-649.

World Health Organisation (WHO) (2013) Cardiovascular Disease. http://www.who.int/mediacentre/factsheets/fs317/en/ 